Global Conferences Series:

Sciences and Technology (GCSST), Volume 3, 2020

The $1^{\text {st }}$ International Conference on Education, Sciences and Technology

DOI: https://doi.org/10.32698/tech3247

\title{
The influence of entrepreneurship training, individual commitment and business motivation toward the small businesses performance in city of parepare
}

\author{
M Rakib ${ }^{1}$, M Azis $^{2}$, DASanusi $^{3}$ and Marwan ${ }^{4}$ \\ ${ }^{12}$ Universitas Negeri Makassar, ${ }^{3}$ Universitas Satya Wiyata Mandala \\ 4 Universitas Negeri Padang
}

\begin{abstract}
The presence of entrepreneurs has been proven to bring benefits to the economic growth of a country. To grow new entrepreneurs, there is a need to improve the quality of human resources through entrepreneurship training, business motivation, and individual commitment. The purpose of this study was to determine the effect of entrepreneurial training, business motivation, and individual commitment toward the business performance in the City of Parepare. This study uses a quantitative method approach. The population in this study was 150 small-scale entrepreneurs who had received entrepreneurship assistance and training in the city of Parepare and determined the number of samples based on Slovin formula as many as 109 respondents, and were taken by proportional random sampling. Data collection was done using a questionnaire and analyzed by SEM analysis. The results of the study show that (1) entrepreneurship training and individual commitment directly influence business Fakmotivation, (2) training, individual commitment, and motivation to work directly influence business performance, and (3) entrepreneurship training and indirect commitment of influential individuals on business performance through business motivation.
\end{abstract}

Keywords: Entrepreneurship Training, Individual Commitment, Business Motivation, Business Performance

\section{Introduction}

The role of entrepreneurship in Indonesia can be seen in the contribution of small and medium enterprises (SMEs) to the national economy. Macroeconomically, small and medium enterprises (SMEs) can be seen as one of the saviors in the process of national economic recovery. Its role in pushing the pace of economic growth and absorption of labor is expected to be the first step for efforts to move the production sector in various business fields.

The development of small businesses in Indonesia has increased from year to year. The supporting factor is that small businesses need small capital and do not need special skills. Government policies provide training for novice entrepreneurs and the provision of low interest loans and easy requirements.

Small businesses are one of the livelihoods of the people in the city of Parepare who experience various obstacles in maintaining their sustainability. Based on observations in the field, the Parepare City Government in this case the relevant agencies in Parepare City such as the Department of Trade, tried to improve the performance of small businesses through small and medium business empowerment programs in Parepare City, revolving fund assistance programs, and education and training, but have not shown improvement significant business performance. This is very much determined by the factor of human resources (entrepreneurship). Entrepreneurs in question are those who have skills through training, commitment and high motivation. 
Providing entrepreneurship training to small business owners is needed to improve entrepreneurial skills in identifying and developing existing business opportunities, building business networks, and determining the most appropriate business strategies. Entrepreneurs who have these abilities greatly affect the performance of their business.

Furthermore, commitment factors also affect business performance. An entrepreneur in order to be successful in managing his business or improving the performance of his business must have a high commitment. Without this commitment, an entrepreneur will fail because he is unable to guarantee the sustainability of his business.

Another factor that is equally important in influencing small performance is motivation to try. Motivation of trying individuals or teams is given in their assignments or work which can affect all aspects of business performance. Stefanovic, Rankovic and Prokic (2011) investigated the motivational factors in order to determine entrepreneurial behaviors in Serbia, based on literature in the area, motivational factors influenced the entrepreneur's behavior towards their business performance and success. [1]

\subsection{Entrepreneurship training}

Training is an effort to improve the quality of human resources in the world of work. Employees, whether new or working, need to take part in training because of job demands that can change due to changes in work environment, strategy, etc. (Dessler, 2017). [2] According to Chusway B (1994) training is the process of teaching expertise and providing necessary knowledge, as well as attitudes so that they can carry out their responsibilities in accordance with standards. [3] Based on the opinions of the experts, it can be stated that business training is an effort that is carried out through the improvement of business skills possessed by entrepreneurs by increasing knowledge, attitudes, and skills.

\subsection{Individual Commitment}

According to Meyer and Herscovitch (2001), the commitment that forces individuals to course of action that is of relevance to a particular target. [4] Meyer and Allen (1993), identified three different components in defining commitments, namely commitment as a bond or affective attachment to the organization, commitment as a perceived cost associated with leaving the organization, and commitment as an obligation to stay within the organization. The three forms of these components are referred to as affective commitment, countinuance commitment, and normative commitment. [5] The expert opinion emphasizes the meaning of individual commitment as an individual's condition bound by his actions, giving rise to beliefs that support his activities and involvement.

\subsection{Business Motivation}

Pamela and Oloko (2015) Motivation is the key to successful organizations to maintain the continuity of work in the organization by means and strong assistance to survive. [6] Motivation is to provide the right guidance or direction, resources and rewards so that they are inspired and interested in working the way you want. Chukwuma and Obiefuna (2014), motivation is the process of generating behavior, maintaining behavioral progress, and channeling specific behavioral actions. [7] From the opinion about motivation, it can be concluded that motivation has an understanding of someone's impulse to do something that is caused by internal and external factors which are realized by action to achieve the objectives of these factors. It is intended that by motivation trying to be able to give energy that moves all the potential that exists, creates high and noble desires, and increases shared enthusiasm. To measure business motivation, indicators were developed by Herzberg in Robbins (2001), including intrinsic motivation from: (1) progress, (2) recognition, and (3) responsibility and extrinsic motivation consisting of: (4) supervision, (5) salary, (6) company policy and (7) work conditions. [8]

\subsection{Small business Performance}

Analyzing business success is by knowing the performance of a business that can be formulated through a comparison of the value generated from a business and the expected value by utilizing the resources owned. Performance measurement can be seen from (a) growth, (b) accounting measurements, (c) stakeholder approaches, (d) present value approaches, (e) customers, (f) internal business processes, and (g) learning. [9] Business performance is the output of these various factors, which is therefore very important to determine the level of adaptability of the business to its environment (Kaplan and Norton, 1996). [9] 


\section{Method}

This study uses a quantitative method approach. The population in this study was all small entrepreneurs who had received assistance and training in the city of Parepare as many as 150 people. For sample determination using Slovin formula. [10].The number of samples was 109 people, and the sample was taken by proportional random sampling based on the type of entrepreneurship training carried out by the municipal government of Parepare. Data collection research was conducted using a questionnaire to obtain primary data. Data is processed and analyzed using Stuctural Equation Model (SEM) analysis.

\section{Result and discussion}

\subsection{Research Result}

The structural test results of the model are evaluated based on the goodness of fit indices whose results can be seen in the following table.

Tabel1.EvaluationCriteriaGoodnessOf Fit Indices Overall Model

\begin{tabular}{lccc}
\hline Goodness of fit Index & Cut-off Value & Result Model $*)$ & Information \\
\hline $\mathrm{X}^{2}$ (Chi Square) & The smallest & 160,327 & Good \\
Probability & $\geq 0,05$ & 0,750 & Good \\
CMIN/df & $\leq 2,00$ & 0,822 & Good \\
GFI/Goodnes of Fit & $\geq 0,90$ & 0,931 & Good \\
AGFI (Ajusted Goodness & $\geq 0,90$ & 0,916 & Good \\
of Index) & $\geq 0,95$ & 1,310 & Good \\
TLI & $\geq 0,95$ & 1,000 & Good \\
CFI (Comparative Fit & $\leq 0,08$ & 0,000 & Good \\
Index) & & & \\
RMSEA &
\end{tabular}

Table 1 shows a summary of the results obtained in the analysis and recommended values for measuring the feasibility of the model. The results of the model feasibility test on structural models show that the addition of several error correlations. All criteria for good status, at AGFI with a value of 0.916, Hair, et. $\mathrm{Al}$ (2012) recommends a value of more than 0.90. [11] The GFI value of 0.931 means that $93.1 \%$ of the population covariance matrix can be explained by the sample covariance matrix. The results of the analysis on other criteria are in good status because they have the results of calculations that meet the recommendation value.

The result of the model test with chi-square yield 160,327 with a probability of 0.750 . This result explains that empirical data is not different from the proposed model (prob.> 0.05). The RMSEA value is a model indicator that measures the deviation of the parameter values of a model with its population covariance matrix (Browne and Cudek, 1993). [12] The RMSEA value of 0,000 has met the recommended recommendation criterion which is below 0.08 , so the feasibility of the model based on RMSEA is good. The AGFI value in this analysis is 0.916 . The model feasibility index with Tucker Lewis Index (TLI) recommends a value of more than 0.95 , and the results of the model calculation have reached 1.310. Similarly, the feasibility index with the Comparative Fit Index (CFI) recommends a value of more than 0.95 and the calculation results have reached 1,000.

The results in the structural model have shown that all the criteria used have good values. In other words, from the evaluation model proposed that the evaluation of the model using the parsimony principle (simple) as a whole from various criteria turned out to have met the requirements so that the model can be stated in accordance with the data.

In addition, the evaluation of the proposed model shows that the evaluation of the model for the overall variable has yielded the above critical value, so it can be stated that the model is acceptable or in accordance with the data, because the instructions from the modification indices are no longer available so that the model can be tested.

The results of the direct effect, the indirect effect, and the total effect between variables in the hypothesized model can be seen in Table 2 below 
Table 2Testing of Direct and Indirect Effects

\begin{tabular}{|c|c|c|c|c|c|}
\hline \multirow[b]{2}{*}{ Independent Variabel } & \multirow[b]{2}{*}{ Dependent Variabel } & \multicolumn{3}{|c|}{ The Effect } & \multirow{2}{*}{$\begin{array}{l}\text { The } \\
\text { comparison } \\
\text { of Effect }\end{array}$} \\
\hline & & Direct & Indirect & Total & \\
\hline Entrepreneurship training & Small business performance & 0,052 & 0,035 & 0,085 & $\mathrm{DE}<\mathrm{IE}$ \\
\hline Individual Commitment & Small business performance & 0,127 & 0,198 & 0,325 & $\mathrm{DE}<\mathrm{IE}$ \\
\hline Working Motivation & Small business performance & 0,198 & 0,000 & 0,198 & $\mathrm{DE}=\mathrm{IE}$ \\
\hline Entrepreneurship training & BusinessMotivation & 0,178 & 0,000 & 0,178 & $\mathrm{DE}=\mathrm{IE}$ \\
\hline Individual Commitment & BusinessMotivation & 0,931 & 0,000 & 0,931 & $\mathrm{DE}=\mathrm{IE}$ \\
\hline
\end{tabular}

Table 2 shows the magnitude of direct, indirect, and total influence between variables. From the comparison of the total influence and the direct effect it can be seen that there are three influence lines between variables which have the same total effect with the direct effect of the effect of trying motivation on small business performance, the effect of entrepreneurship training on trying motivation, and the influence of individual commitment to motivation to try. This means that these three lines do not have indirect influence. There are two pathways that have a total influence greater than the direct effect, namely the influence of entrepreneurship training on small business performance and the influence of individual commitment to the performance of small businesses. This means that there is additional influence through indirect channels.

In the next discussion, the results of the test will be elaborated on 6 (six) hypotheses proposed in this study. For the rejection or acceptance of the research hypothesis based on the CR value, where the CR value is less than 2,000 and the $\mathrm{p}$-value $\geq 0.05$ indicates the hypothesis that the causal relationship is rejected, while the $\mathrm{CR}$ value is more than 2,000 and the p-value $<0.05$ indicates the hypothesis the causal relationship is accepted.

The test results of the test hypotheses model the effect of entrepreneurship training, individual commitment, and motivation to strive for small business performance, the overall model shows a significant number. For more details, see Table 2 below.

Table 3.The Hypotheses Testing of the Effect of Entrepreneurship Training, Individual Commitment, and Business Motivationtoward Small Business Performance.

\begin{tabular}{lcccc}
\hline \multicolumn{1}{c}{ Types of Effect } & $\begin{array}{c}\text { Loading } \\
\text { Factor }\end{array}$ & CR & Prob. & Information \\
\hline Entrepreneurship training -> Business performance & 0,209 & 3,455 & 0,000 & Significant \\
Individual Commitment->Business performance & 0,398 & 4,435 & 0,000 & Significant \\
Business Motivation ->Business performance & 0,526 & 4,766 & 0,000 & Significant \\
Entrepreneurship training -> Business Motivation & 0,281 & 6,169 & 0,000 & Significant \\
Individual Commitment->Business Motivation & 1,163 & 8,689 & 0,000 & Significant \\
\hline
\end{tabular}

The resultin this study are entrepreneurshiptraining, individual commitment, andbusiness motivation significantly influences the performance of small businesses in the City of Parepare both directly and indirectly. For more details, the following model can be described.

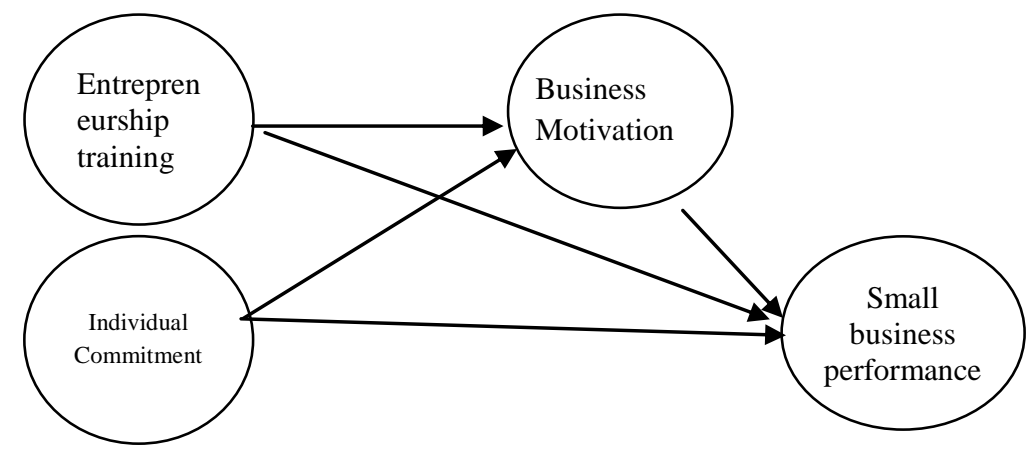

Figure 1. Model Effect of Entrepreneurship Training, Individual Commitment, and Business Motivation on Small Business Performance 


\subsection{Discussion}

\subsubsection{Theeffect of Entrepreneurship Training on the small businesses performance}

The result of hypothesis testing1 indicates that entrepreneurship training has a positive and significant effect directly on the performance of small businesses at 0.050 . This is known from the critical ratio (C.R) between entrepreneurial training variables with small performance of 3.455 or C.R $>2.0$. With a probability value of 0,000 which is smaller than 0.05 or $\rho(0,000)<$ cut of value $(0.05)$. The results of this study are in line with the results of the Mayuran L (2016) study that found that the Entrepreneurship training was significant for performance of Small Enterprises. [13] Furthermore, according to Kithae P P (2013) that entrepreneurship training has had a substantial impact on performance of entrepreneurs. [14] The results of the study are King'ori G N and Theuri F S (2016) that entrepreneurship training was found to have substantial performance as enterprises thus influencing the growth of businesses.[15]

\subsubsection{Effect of individual commitment to the performance of small businesses}

The result of hypothesis testing 2 indicate that individual commitment has a positive and significant effect directly on the performance of small businesses at 0.127 . This is known from the CR value between individual commitment variables with small business performance of 4.435 or CR> 2.0 with a probability value of 0,000 which is smaller than 0.05 or $\rho(0,000)<$ cut of value $(0.05)$. The results of this study are supported by the results of Simon M's research, Stachel C, and Covin, J G (2011) shows that Entrepreneurship Orientation and commitment improve performance.[16]

\subsubsection{The Effect of Business Motivation on Small Business Performance}

The result of hypothesis testing 3 indicates that motivation seeks a positive and significant direct effect on the performance of small businesses at 0.198. It is known from the CR value between the motivation motivational variable and the small business performance of 4.766 or CR> 2.0 with a probability value of 0,000 which is smaller than 0.05 or $\rho(0,000)<$ cut of value $(0.05)$. The results of this study are in line with the results of the study of Robichaud, McGraw and Alain (2001) conducted research to establish a relationship between entrepreneurial performance and entrepreneurs' motivation; the study discovered that, there is a correlation between the entrepreneur motivational factors and the business performance.[17] The results of the same study by Aftan Y and Hanapi M (2018) that entrepreneurial motivation has a significant relationship with the performance of small businesses.[18]

\subsubsection{Entrepreneurship Training on Business Motivation}

The result of hypothesis testing 4 indicates that entrepreneurship training has a direct positive and significant effect on trying motivation of 0.178 . This is known from the $\mathrm{CR}$ value between entrepreneurship training variables and business motivation of 6.169 or CR> 2.0 with a probability value of 0,000 which is smaller than 0.05 or $\rho(0,000)<$ cut of value $(0.05)$. The results of this study are supported by the opinion of Lukasik K (2017) that companies should pay attention to enter more useful trainings because they are in greater extent they motivate employees. [19]

\subsubsection{The effect of Individual Commitments on Business Motivation}

The resultof hypothesis testing 5 shows that individual commitment has a direct positive and significant effect on business motivation of 0.931. This is known from the CR value between entrepreneurship training variables with attempted motivation of 8.869 or $\mathrm{CR}>2.0$ with a probability value of 0,000 smaller than 0.05 or $\rho(0,000)<$ cut of value $(0.05)$. This is consistent with the opinion of Meyer J P, Becker T E, and Vandenberghe C (2004) that employees who have a stronger affective commitment to the target experience greater intrinsic motivation.[20]

3.2.6 The Influence of Entrepreneurship Training and Commitment of Individuals through business motivation toward Small Business Performance.

The result of hypothesis testing 6 indicates that entrepreneurship training and individual commitment through business motivation positively influence the performance of small businesses. The results of this study are in line with the results of Kalkavan and Katrinli's research (2014), that commitment has a significant positive effect on employee performance, through work motivation.[21] 


\section{Conclusion}

Based on the resultof the research and discussion, the following conclusions can be stated.

1. Entrepreneurship training and individual commitment have a direct and significant effect toward business motivation.

2. Entrepreneurship training, individual commitment, and business motivation have a direct and significant influence on the performance of small businesses.

3. Entrepreneurship training and individual commitment indirectly and business motivation significantly influences the performance of small businesses.

\section{References}

[1] StefanovićI.,RankovićLandProkićS 2011Entrepreneurs'motivationalfactors:Empirical evidencefromSerbia.Serbian JournalofManagement. Vol. 6(1). v 73-83.

[2] Dessker G 2017 Human Resource Management. The Fifteenth Edition. London, England: Pearson Education.

[3] Cushway B 1994 Human Resource Management: Planning - Analysis - Performance - Reward. London: Kogan Page.

[4] Meyer, J. P., \&Herscovitch, L. (2001). Commitment in the workplace: Towardageneralmodel.HumanResourceManagementReview,11, p 299-326.

[5] Meyer J P, Allen N and Smith C A 1993 Commitment to Organizations and Occupations: Extension and Test of a Three-Component Conceptualizatio Journal of Applied Psychology Vol. 78(4) p 538-551. DOI: 10.1037/0021-9010.78.4.538.

[6] PamelaAOandOloko2015EffectofMotivationonEmployeePerformance of CommercialBanksinKenya:ACaseStudy ofKenyaCommercialBankin MigoriCounty.Journal of Human ResourceStudies Vol. 5 (2), p 87-103. Doi: 10.5296/ijhrs.v5i2.7504.

[7] Chukwuma,E.M.,\&Obiefuna,O.(2014).EffectofMotivationon Employee Productivity:AStudy ofManufacturingCompaniesinNnewi.Journalof ManagerialStudies and Research Vol. 2 (7), v $137-147$.

[8] Robbins, S.P. (2001) Organizational Behavior. 9th Edition, New York: Prentice-Hall, Inc.

[9] Kaplan, RS, and D.P. Norton 1996. The Balanced Scorecard, Translating Strategy into Action.. Boston: Harvard Business School.

[11] Hair J F. Sarstedt M. Ringle C M. and Mena JA 2012 An assessment of the use of partial least squares structural equation modeling in marketing researchJournal of the Academy of Marketing Science 40 (3), p 414-433.

「101 Slovin M J 1960 Sampling. New York: Simon and Schuster Inc.

[12] Browne M W and Cudeck R1993 Alternative Wavs of Assessing Model Fit. In K. A. Bollen \& J. S. Long (Eds.), Testing Structural Models. Newburg Park, CA: Sage.

[13] MayuranLogendran $2016 \quad$ ImpactofEntrepreneurshipTrainingonPerf ormanceof SmallEnterprisesinJaffnaDistrict. Global Journal of Commerce \&Mangement Perspective, Vol. $5(2), \mathrm{p} 1-6$.

[14] KithaePP $2013 \quad$ ImpactOfEntrepreneurshipTrainingOnPerformanceOf MicroAndSmallEnterprises(Mses)InKenya:ACaseStudyofEmbuMunicipality. International Journal of Business and Management Review, Vol. 1 (2), 1-7.

[15] King'ori G N and Theuri F S 2016 The Role of Entrepreneurship Training and Education in Enhancing Growth of Small and Medium Enterprises in Kenya: A Case Study of Mombasa County. IOSR Journal of Humanities and Social Science (IOSR-JHSS). Vol. 21 (Issue 4), p $97-106$.

[16] Simon M, Stachel C, and Covin J G 2011 The effects of entrepreneurial orientation and commitment to objectives on performance, New England Journal of Entrepreneurship, Vol. 14 (Issue: 2), p 9-17, https://doi.org/10.1108/NEJE-14-02-2011-B001

[17] Robichaud, McGraw and Alain 2001 Toward the Development of a Measuring Instrument for Entrepreneurial Motivation. Journal of Developmental Entrepreneurship, Vol.6(1), p 189-201.

[18] Aftan Y andHanapi M 2018 TheImpactofEntrepreneurialMotivation onSmallBusiness Performancein Iraq. International Journal of Academic Research in Business and Social Sciences, Vol. 8 (1). P 409-419. http://dx.doi.org/10.6007/IJARBSS/v8-i1/3816

[19] ŁukasikKatarzyna 2017 TheImpactOf TrainingOnEmployees MotivationInSmesIndustry. ZeszytyNaukowePolitechnikiCzestochowskiejZarzadzanieNr $28 \mathrm{t} . \quad 1, \mathrm{~s} .96-109 . \quad$ DOI: 10.17512/znpcz.2017.4.1.08.

[20] Meyer J P, Becker T E, and Vandenberghe C 2004 Employee Commitment Comunitment and Motivation: A Conceptual Analysis and Integrative Model. Journal of Applied Psychology. Vol.89(6), p 991-1007.

[21] Kalkavan, Salma dan Alev Katrinli. 2014 The Effects of Managerial Coaching Behaviors on The Employees Perception of Job Satisfaction, Organisational Commitment, and Job Performance: 
RedWhitepress Global Conferences Series: Sciences and Technology (GCSST), Volume 3, 2020

Case Study on Insurance Industry in Tutkey. Journal of Social and Behavioral Sciences. Vol.150. p 1137-1147. 